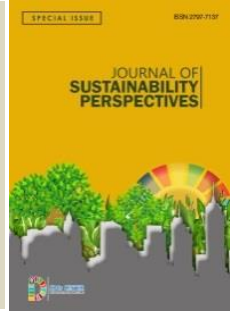

\title{
Namal Institute: A Mission for Rural Uplift, Sustainable Development, and Social Impact
}

\author{
Yasir Riaz ${ }^{1, *}$ \\ ${ }^{1}$ Namal Institute, 30 KM Talagang Road, Mianwali, Pakistan, \\ *corresponding author: yasir.riaz@namal.edu.pk
}

\section{Article Info}

Received:

15 March 2021

Accepted:

25 May 2021

Published:

1 August 2021

DOI:

Presented in The $6^{\text {th }}$ International (Virtual) Workshop on UI GreenMetric World University Rankings (IWGM 2020)

\begin{abstract}
Namal Institute was established by Mr. Imran Khan, a famous philanthropist and the current Prime Minister of Pakistan, with a mission for rural uplift and development through educating bright youth and offering innovative solutions to rural challenges through research by highly trained academics. The majority of the Namal's students belong to rural areas, and $97 \%$ of them secured scholarship either due to meritorious educational background or being unable to afford education (i.e., needbased scholarship). To ensure quality, Namal has kept a student-faculty ratio of 10:1. It is one of the pioneering institutes focusing on Agribusiness and Agri-tech education in Pakistan. It has a beautiful campus comprising of 1000 Acres land located in the Salt Range in an area consisting of hills and crags overlooking Namal Lake in the Mianwali District. To foster its sustainability efforts, Namal has planted an olive garden on an area of 4 acres. Recently, two new blocks have been constructed using environmentfriendly material (e.g., mud blocks, solar-powered LED lights, etc.). Various student societies in Namal Institute have also taken different environmental and social initiatives in the rural area. Primarily during the corona pandemic, the Namal Society for Social Impact (NSSI) has managed to deliver ration packages to the deserving low-income families of the rural area. The medical and administrative staff has distributed essential protection material to the hospitals/doctors in the rural area.
\end{abstract}

\section{Keyword:}

rural uplift, free education, sustainable development, social impact, green architecture

\section{Introduction}

Namal Institute is one of the youngest higher education institutes of Pakistan. It is a not-for-profit private university established by Mr. Imran Khan, the current Prime Minister of Pakistan, in the Mianwali District of Punjab, Pakistan. It was initially started as a technical training college in 2008. It offered short certificate courses and diplomas to the underprivileged youth in the rural area of the district Mianwali. However, a modest starting from a technical training college turned out to be the biggest cause in the country. During 
the same year, it started offering its first-degree program being an associate college of the University of Bradford, United Kingdom (UK). It remained an affiliated college of the University of Bradford, England, from 2008-2016 and the University of Engineering and Technology, Lahore, Pakistan, from 2017-2018. In early 2019, Namal has been granted degree-awarding institute status. Namal institute is envisioned to build an educational institute that evolves into one of the largest university towns in Pakistan, known by the name of Namal Knowledge City.

Namal Institute constitutes a total of 1000 acres of land in the Namal Valley in District Mianwali. The hills and crags surround the Namal Institute on the western side, known as the Salt Range of Pakistan. Pakistan's Salt Range is a hill system that is well known internationally for the extensive deposits of rock salt. On the eastern side, Namal lake surrounds Namal Institute. The lake has a rocky bank offering stunning sunset views. The area around the Namal Institute has numerous wildlife sanctuaries and a high level of biodiversity. The terrain is suited to an eco-progressive lifestyle that enhances Namal's academic experience. The area has hills with hidden Sulphur springs, spectacular eyecatching sceneries, and a historical and old Namal lake with a dam built in 1913 by the British Government.
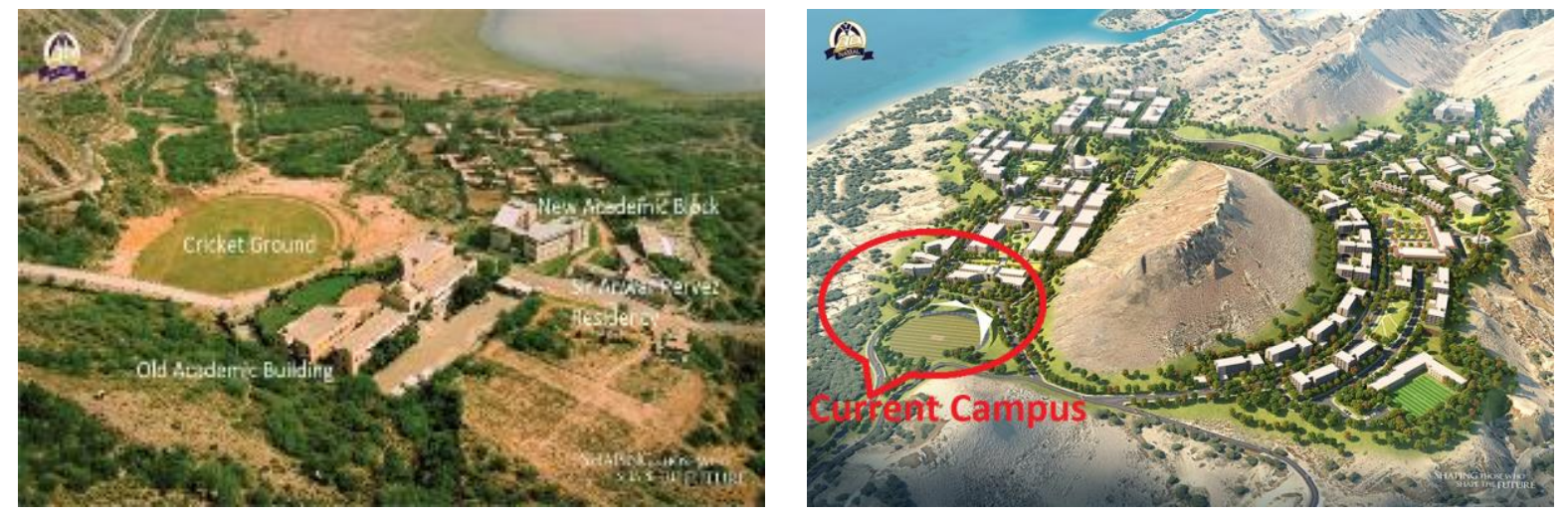

Figure 1: Current campus (on the left) and planned campus (on the right) of Namal Institute, Mianwali. The current campus consists of a cricket ground, old academic building, new academic block, Sir Anwar Parvez Khan Residency, and adjoining Namal lake and the mountain.

\section{Rural Uplift}

Namal Institute is the only higher education institute in Pakistan that has a mission for rural uplift and development. Its mission is: "To become a center of academic excellence for rural uplift and development through:

- Educating bright youth who have Namal values and will contribute to organizations and community.

- Finding innovative solutions to rural challenges by highly trained academics."

Namal has been working tirelessly for its mission since its inception. For educating bright youth, Namal offers generous merit as well as need-based scholarships. The majority of the Namal's students belong to rural areas, and $97 \%$ of them secured scholarship either due to meritorious educational background or being unable to afford education (i.e., needbased scholarship). To encourage female students, Namal provides free hostel facility to them. Students from 60 different districts of Pakistan are benefiting from this unique 
opportunity in the rural area of the district Mianwali. Namal also provides free of cost shuttle service to its community to and from the nearby areas. Currently, Namal Institute offers undergraduate degrees in business administration, computer science, electrical engineering, and mathematics. To maintain the highest quality of education, Namal has maintained a student-teacher ratio of 1:10. Namal also offers student assistantships to the deserving students under the work-study program where students are paid to work under various schemes.

Namal Institute is one of the pioneering institutes in the country that focuses on Agribusiness and Agritech education in Pakistan. Agriculture is one of the primary sources of livelihood in rural Pakistan. It also contributes a significant portion to the GDP of Pakistan. Namal has also inaugurated Nisar Aziz Agritech Center on July 19, 2019, to foster contributions in the agriculture sector through innovative research and academic activities. The primary object and purpose of setting up the center is to impart modern agricultural education and training to the youth and farmers of the impoverished communities to enable them to learn low cost modern farming techniques to address the agricultural problems through effective technological solutions. Currently, the Agritech Center is working on the following four projects: (1) diagnosis of crop diseases through image analysis and machine learning, (2) analysis of soil quality through image analysis and machine learning, (3) managing pre and post-harvest loses of commercial crops and predict storage losses through loT and machine learning, and (4) agricultural value chain and market survey.

Another center, Namal Artificial Intelligence \& Big Data Center, has also been recently established with the vision to evolve as a center of excellence of artificial intelligence, machine learning and data science focusing on the rural challenges. The center encourages the research projects of applied nature and rural relevance. The preferred research themes of the center include artificial intelligence for life, artificial intelligence everywhere, pure artificial intelligence, and artificial intelligence for hardware and hardware for artificial intelligence. The center will be establishing dedicated laboratories for different streams that will work towards the goal of the center.

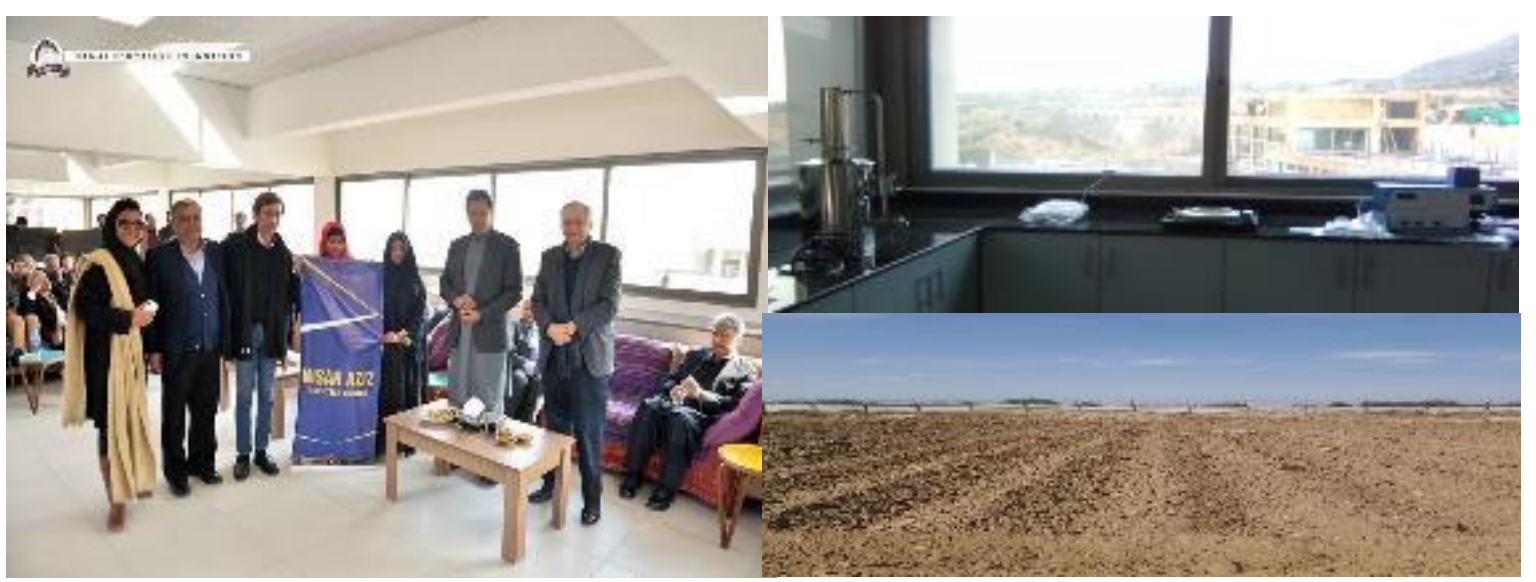

Figure 2: Inauguration of Agritech Center on July 19, 2019 (on the left), soil testing laboratory (on upper-right), and field lab for vegetable and organic crops planting (on lower-left). Mr. Imran Khan, Prime Minister of Pakistan and the Chairperson of Namal Knowledge City, inaugurated Agritech Center at the newly constructed Academic Block of Namal Institute Mianwali along with Mr. Ashar Aziz, CEO, Skyelectric, Dr. Arif Nazir Butt, Acting Rector, and Member, Board of Governors, and Mr. Abdul Razak Dawood, Member Board of Governors, Namal Knowledge City. 
Rural and Agriculture Informatics Lab (RAIL) at Namal Institute has developed an expert system that can diagnose the common diseases of four livestock animals buffalo, cattle, goat, and sheep [1]. The system diagnosis the suspected disease after collecting different symptoms through an easy to use interface. After diagnosis, the user is also given a suggestion about the possible treatment of the disease. The application is named as "Mera Maweshi," meaning my cattle in English and is available at http://meramaweshi.com/.

\section{Sustainable Development}

Protection of the natural, physical, and social environment is one of the fundamental ideas behind the establishment of the Namal Knowledge City. Namal aims to cultivate a culture of environmental sustainability and protection to provide its students with a professional and academic environment that is essential for the progressive and prosperous Pakistan. Namal Institute offers four-degree programs, and all have a primary focus on sustainability. Namal Institute's mission is to become a center of academic excellence for rural uplift and development, and it has been given special attention while designing the curriculum of all the courses. All courses offered at Namal are focused on sustainability. For example, it offers the following essential courses in the degree programs: civic engagement and social impact, entrepreneurship, environment, and sustainable agriculture, agriinformatics, agribusiness, renewable energy sources, and artificial intelligence and machine learning applications for sustainable development.

To foster its sustainability efforts, Namal has planted (1000 olive trees in) an olive garden on an area of 4 acres on the institute's land [2]. It was carried out by the primary collaboration of the Barani Agriculture Research Institute (BARI), Chakwal, Pakistan. For the development of the garden, BARI extended not only the technical support but in the form of Arbequina Olive Trees. It is a distinct olive tree species that are imported from Spain and is a well-known olive tree internationally. The initiative to plant olive trees is full of promise for the sustainability and rural uplift and demonstrates the strong commitment of Namal. On August 14, 2020, Namal Institute has planted 2000 (different types of) trees to take part in the prime minister campaign for planting 3.5 million trees countrywide.

Recently, Namal has constructed two new blocks, namely, Namal Academic Block-1 and Sir Anwar Pervez Residency using environment-friendly material [3]. These blocks are one of a kind in Pakistan constructed using sun-dried mud-blocks emphasizing commitment towards sustainability. Namal Institute realizes the importance of energy savings. These new buildings entirely consist of LED lights and fully automated control systems for air conditioning and ventilation. The lights and electric appliances in the old-academic building are also being replaced with new energy-efficient appliances. In all the buildings, special attention is given to the passive systems for natural light exploitation. New buildings will also be equipped with renewable energy sources. The installation of solar panels for a complete solar-based electric power system on the building roofs is in process. The base for the solar plates has been installed, as displayed in Figure 3. We expect to completely switch this building to solar energy at the end of this academic year. Currently, we have installed solar geysers for the upcoming winter season. 

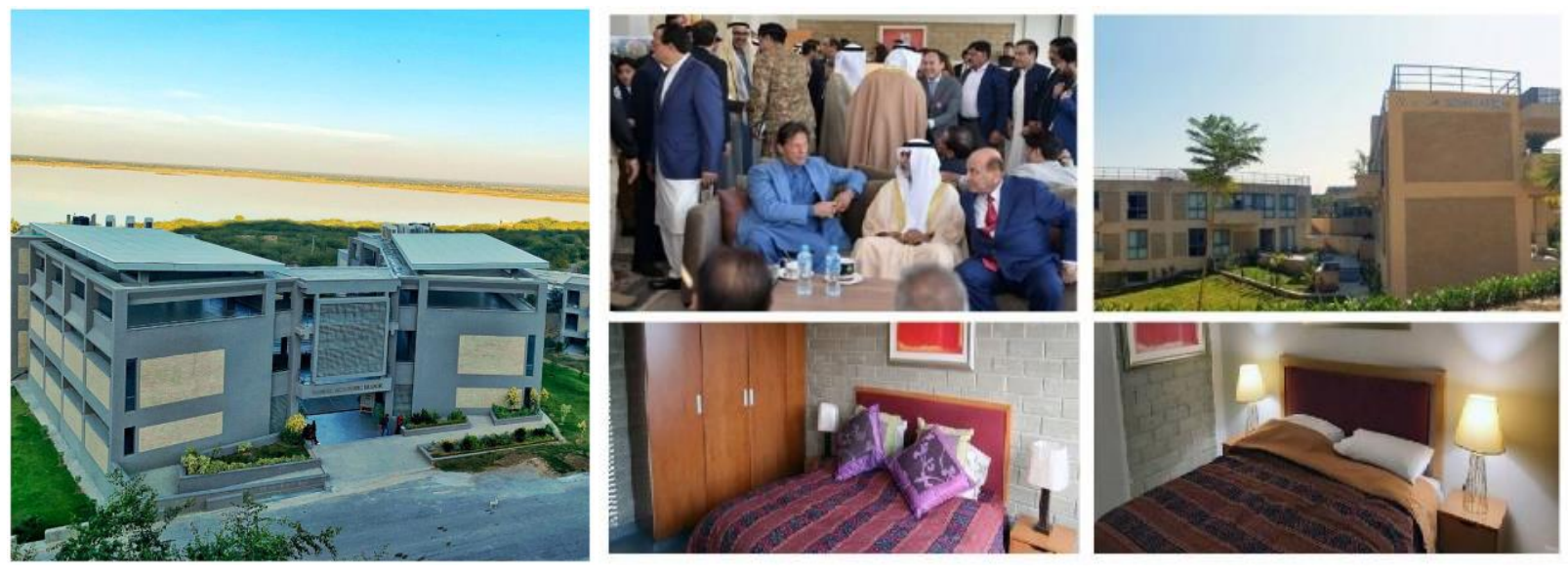

Figure 3: New academic block (on the left) and Sir Anwar Pervez Residency (on right and center) constructed using environment-friendly material.

Namal Institute has applied for the Leeds Consultant Certification, and it is under process. Institute hopes to achieve a platinum certificate by the consultants. Otherwise, the buildings are fully ventilated, open to natural light, and full of greenery. The buildings are enveloped by breathtaking sights of the exquisite Namal Valley overlooking the Namal Lake, aiming to become a hub of pioneering academic excellence.

Namal Institute is further planning to launch the Center of Environment and Indus Valley Civilization during the coming years [4]. The sole purpose of this Center will be to support the research on the environment, sustainability, and the Indus valley history and future developments.

\section{Social Impact}

The social impact is one of the fundamental key values at Namal. Namal offers various programs of community service to train its students to uphold the spirit of giving back to society. Different student societies in Namal Institute have taken various environmental and social initiatives in rural areas. For example, the Namal Society for Social Impact (NSSI) provides free tuition to 200+ underprivileged students belonging to the nearby villages. It also organizes blood donation drives for the needy. Especially during the corona pandemic, NSSI was at the forefront of the efforts to curb the adverse economic conditions brought by the COVID-19 pandemic. NSSI managed to deliver hygiene kits and ration packages to the 60 deserving low-income families of the rural areas surrounding Namal. The medical and administrative staff has distributed essential protection material to the hospitals/doctors in the adjoining rural area.

Namal has introduced a concept of Time Bank to achieve three pillars of change, namely sustainability, student development, and social development. Under this initiative, all students are required to contribute 320 hours of community service every year. Students maintain social and work time accounts with students support office and deposit their hours spent in community services as well as on other work assignments at the campus in the time accounts every month. Community services include the collection of waste, waste recycling, tuition services for school-going children, farms management (olive or vegetable farms, etc.), and plantation drives in the community, etc.

Namal's students are playing a key role in social and community services and having a positive impact on society. Mr. Muhammad Salman, a student at Namal, is on a mission to 
create an economical version of the ventilator, which will cost a fraction of the price of a conventional ventilator. He will be using locally sourced materials to bring the cost down. Another student, Mr. Hafiz Awais Afzal, has started a social enterprise with the sole purpose to make higher education accessible and affordable to all students of Pakistan and to ensure the availability of equal opportunities to students across the country. It offers guidance, application processing, and consultancy to help students navigate through their future academic and professional journey. There are many other students at Namal that have started similar projects to help out the society in solving the more significant problems.

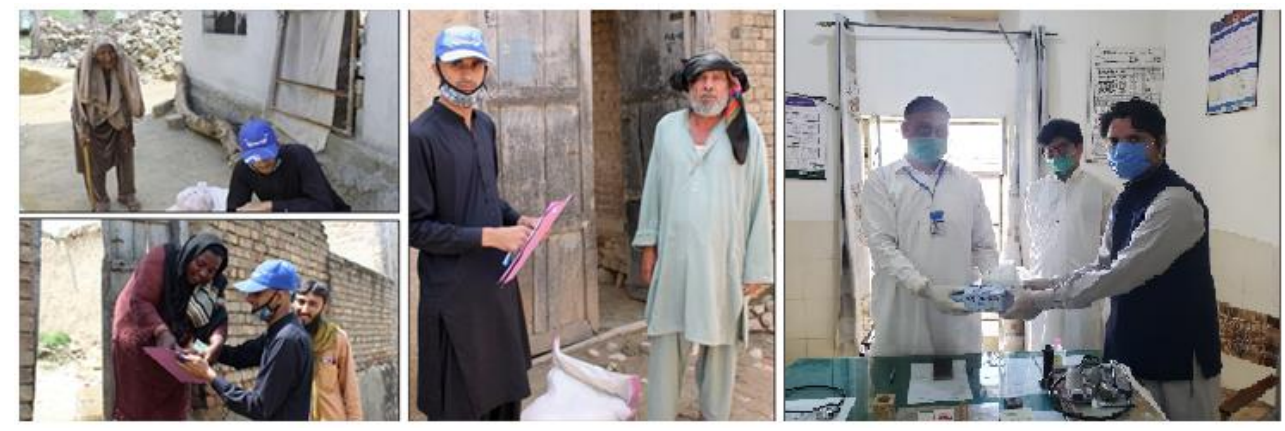

Figure 4: COVID-19 Initiatives taken by NSSI (on right and Center) and administrative staff (on the left).

Namal Environmental Society runs several awareness campaigns, organic gardening seminars, and has established a fossils museum to educate students about our enriched geological structures. Namal's objective is to be the leading sustainability practitioner in the academic world in the region. Namal is inculcating these values in the students by ensuring the use of environment-friendly procedures and processes like recycling waste and using renewable energy resources. Namal trains its students to use the knowledge learned during the studies in practical ways, for example, the time bank initiative.

Namal Education Foundation (NEF), the funding body of the Namal Institute, has also started a school in the area to provide quality education to the pupils at a subsidized rate. Namal School focuses explicitly on the analytical skills with problem-solving attitude through interactive, inquiry, and project-based learning. Around 250 students, including the children of faculty and staff, are getting benefit from this opportunity. All the teachers at Namal School are highly qualified (i.e., all are BS/MS qualified). Namal school has a teacher: student ratio of 1:13.

\section{Summary / Concluding Remarks}

The Namal Institute is envisioned to become a high-quality education facility with particular emphasis on rural uplift, sustainability, and social impact. It is determined to become a world-class university as dreamed by its founder, Mr. Imran Khan, who wish to develop it into a knowledge city similar to the University of Oxford, UK. In his own words, "the establishment of Namal Knowledge City brings the vision of a sustainable Pakistan one step closer. Under the multidisciplinary Namal Knowledge City, students will become tomorrow's leaders" [5]. The construction of environment-friendly infrastructure centers for research on environment and sustainability and numerous social activities demonstrates its commitment towards the cause. 


\section{References}

1. Rural and Agriculture Informatics Lab, 2018. Namal College. Available online at http://rail.namal.edu.pk/ accessed on August 23, 2020.

2. Namal Knowledge City, 2020, Namal Knowledge City. Available online at https://www.namalknowledgecity.com/news/olive-tree-plantation accessed on August 17, 2020.

3. Web desk, 2019. Daily Pakistan. Available online at https://en.dailypakistan.com.pk/27Jan-2019/pm-imran-inaugurates-first-academic-block-of-namal-knowledge-city accessed on August 10, 2020.

4. Namal Institute Establishes Two New Centers, 2020, July-September. Namalnama, Issue 8. Available online at https://issuu.com/namalcollege/docs/issue_08_-jul-sep_2020 accessed on August 24, 2020.

5. Namal Institute, 2020. Namal Institute. Available online at https://namal.edu.pk/chairmans-message accessed on August 15, 2020. 